\title{
Concept and Practice of Open-pit Mining Area Restoration and Reuse --- Taking an Open-pit Coal Mining Area in Datong, Shanxi as an Example
}

\author{
Huang Jiayin ${ }^{1}$, Hu Baoan ${ }^{1 *}$, Tan Xiangjun ${ }^{1}$, Cheng Jin $^{1}$ and Li Long ${ }^{1}$ \\ ${ }^{1}$ CCCC (Tianjin) Eco-environmental Protection Design \& Research Institute Co., Ltd.
}

\begin{abstract}
The restoration of open-pit mining coal mine areas is imminent, and it is of great significance to put forward a set of reasonable restoration concepts. According to the geographical location and economic conditions of the mining areas, this paper combines multiple restoration concepts and measures such as "fundamental reforestation", "near-natural restoration", "introduction of agricultural and forestry industries" and "development of cultural tourism in abandoned land" in a scientific way, the combination has been successfully applied in the restoration and comprehensive utilization project in an open-pit coal mine area in Datong, Shanxi, China. This concept realizes the reuse of abandoned open-pit coal mines and closely follows the national strategy of poverty alleviation and rural revitalization, in pursuit of the national vision of "clear waters and green mountains are mountains of gold and silver."
\end{abstract}

\section{Introduction}

In recent years, coal resources still occupy an important position in China's energy structure. According to the "China Energy Big Data Report (2018)" [1], as of 2017, coal energy still accounts for more than $60 \%$ of total energy consumption. Since the 1970s, the environmental management of open-pit mining has been discussed as a major issue at home and abroad ${ }^{[2]}$. John ${ }^{[3]}$ believes that the ecological restoration of open-pit mining areas should not only rely on scientific theories and technologies, but also improving the public's awareness of environmental protection and strengthening environmental management, thus achieving the restoration of open-pit mining areas in terms of both technology and management. Due to the special geological structure and composition of coal mines, the process of coal mining will artificially form dumps, gangues, and open pits, etc. ${ }^{[4]}$ If mining is not strictly performed in accordance with guiding principles, the open pit mining process often causes environmental issues such as soil and water loss, ground subsidence of pits, destruction of biodiversity, and pollution of groundwater by chemical-containing wastewater in the mining process, which has a great impact on the ecological environment, resulting in geological disasters such as mudslide, open-pit mining slope sliding, etc., ${ }^{[5-7]}$ which severely endanger the normal life and economic development of local residents. Wang Deqi and Wang Linlin et al. ${ }^{[8]}$ carried out zone planning and management of mines according to the degree of ecological damage, providing guidance for mine reclamation projects. Experts and scholars at home and abroad have conducted targeted research on the issues of subsidence areas, fly ash yards, barrows, contaminated soil and water in open-pit coal mining areas through methods such as classification statistics, management modeling, and analogy, achieving certain success in some areas. The current restoration of open-pit mining areas mainly includes: greening of openpit mining areas ${ }^{[9]}$, land reclamation ${ }^{[10]}$, ecotourism, botanical parks ${ }^{[11]}$, etc., and have achieved good results in practical applications, however, actual engineering projects lacks applicable conditions for the repair methods of open-pit mining areas and the proper concept and methodology under the guidance of the national strategy in the new era, therefore, by taking a mine repair project in Datong, Shanxi as an example, this paper proposes a repair-and-reuse system for open-pit mining areas, accumulating experience for future mine restoration projects.

\section{Classification of open-pit mining area}

\subsection{Open-pit mining area}

Open pit refers to the "open field" or "cavity" on the ground surface caused by mining activities, which is also called "mined-out zones". An open pit is a place with a complete production system for open-pit mining. A series of open trenches are excavated from the surface to each ore body in the open-pit mine site, and a transport connection between the ground and the production steps (step-shaped working surfaces that are gradually formed during the mining process) is established, forming a

*Corresponding author's e-mail: thyhba $@ 163 . c o m$ 
transportation system between the open-pit mining plant, ore dressing or crushing plant, dump site and industrial square to ensure the normal operation of stripping. Due to coal mining in the open pit, the surface of the rock and soil is stripped, and the original ecosystem is damaged, therefore, the open pit is the main objective of the coal mine repair ${ }^{[12-13]}$.

\subsection{Subsided land}

When coal is mined, the original stress equilibrium state of the rock mass around the mining area is damaged. After the stress is redistributed, a new equilibrium is reached. During this process, continuous movement, deformation, and non-continuous damage such as cracking and falling occur in the rock formations and the surface. This phenomenon is called "mining subsidence." Coal is an important useful layered mineral, its well mining will inevitably cause sink age of rock layers and the ground, leading to the collapse of a large amount of land. This phenomenon is called "coal mining subsidence", and the formation of the subsidence area is called "subsided land" [14-15].

\subsection{Coal gangue yard}

Coal gangue is the solid waste discharged during coal mining and coal washing, it is a kind of dark gray rock that is harder than coal but with low carbon content, which is associated with coal seams during coal formation. It includes the excavation gangue during the roadway excavation, the gangue extracted from the roof, the ground and the interlayer during the excavation, and the gangue picked up from the coal washing process. The main components of gangue are $\mathrm{Al}_{2} \mathrm{O}_{3}, \mathrm{SiO}_{2}$, it also contains varying amount of $\mathrm{Fe}_{2} \mathrm{O}_{3}, \mathrm{CaO}, \mathrm{MgO}, \mathrm{Na}_{2} \mathrm{O}$, $\mathrm{K}_{2} \mathrm{O}, \mathrm{P}_{2} \mathrm{O}_{5}, \mathrm{SO}_{3}$ and rare elements (gallium, vanadium, titanium, cobalt). In the open-pit mining process of coal mines, with the gradual excavation of the bottom coal seam, a large amount of coal gangue is generated and piled up near the mining area. Coal gangue is wasted and occupies a large amount of land, also, the escape or leaching of sulfide from the gangue will pollute the atmosphere, farmland and water bodies ${ }^{[16-17]}$.

\subsection{Dumping site}

Dumping site refers to the place where the mines are stripped and excavated wastes are discharged, and it includes the outer dumping site and the inner dumping site. Due to the presence of mineral exudates, pollutants, waste sediments and other interferences in open-pit mine dumps, soil fertility is reduced, the main nutrients for plant growth are lacking, and the presence of certain toxic chemicals can cause soil's physical and chemical properties to be unsuitable for plant growth. Dumping sites not only cause soil degradation and loss of biodiversity, but also affect surrounding ecosystems and landscapes. Therefore, the ecological restoration of dumping sites requires serious attention ${ }^{[18-19]}$.

\section{Recovery and reuse concept of open-pit mining areas}

\subsection{The concept of "fundamental reforestation" in open-pit mining areas}

The concept of " fundamental reforestation" in open-pit coal mining areas refers to elimination of the geological disasters and attempts to cover exposed rocks and subsided land cracks by planting grass and bushes, with minimal changes to the topography of the mining areas. The purpose of this concept is solely to meet the urgent need to achieve reforestation in a short period of time, usually of regions that are of relatively low economic development and small population density. In these regions, topographical damages caused by mining can be covered by grass and bushes, thus achieving the preliminary reforestation of mines. This concept is applicable in remote mountainous areas, where there are no residents living near the mine, and have lower requirements for the mine landscape.

\subsection{The "near-natural restoration" concept in open-pit mining areas}

The "near-natural restoration" of open-pit mining coal mines refers to a landscape creation with the "tree-bushmethod based on the "fundamental reforestation", this method uses plants that are both economical and suitable to grow in the specific areas. When eliminating geological disasters, instead of traditional techniques such as anchors, hanging nets, and retaining walls, this method utilizes biological anchors and flexible retaining walls that are strong and can be integrated with the landscape, this leads to "near-natural restoration" of mining areas in the mold of the before-damage/original topographical characteristics without any appearance of man-made interferences. This concept is applicable to areas in good economical standing, for example, in areas of a large flow of people such as roads and tourism attractions, especially within the visible range, it is possible to basically restore the natural mountainous landscape, which is previously damaged by open-pit mining.

\subsection{The concept of "introduction of agricultural and forest industries" in open-pit mining areas}

The "introduction of agricultural and forest industries" in open-pit mining areas refers to the formation of large-area platforms or terraces that can be cultivated in the open-pit of the mining area through artificial soil covering or terrain modification. The introduction of economically feasible crops, on the one hand, can make fuller use of abandoned mining areas, on the other hand, it can drive the surrounding economy through agricultural and forest industries and provide employment for former mine workers in the mining area and nearby residents, achieving local and regional poverty alleviation. The applicability of this concept needs to be comprehensively examined: first, the open-pit coal mining area must have 
a large area of bare open ground or a multi-level platform that can be formed by artificial grading; second, there must be a sufficient amount of agricultural soil and water resources around the mining area to support the growth of agricultural and forest crops; finally there needs to be convenient transportation near the mining area to facilitate the rapid transportation of agricultural and forest products. In addition, the mining area needs to be located at a location where the multiple harvests of crops can happen in a year to achieve a balance between the transformation of the mining area and economic returns.

\subsection{The concept of "cultural tourism development of abandoned land" in open- pit mining areas}

The "cultural tourism development of abandoned land" in open-pit mining coal mines refers to the combination of the cultural heritage of the region and the development of cultural tourism industries using the abandoned mining areas. From the perspectives of science popularization, education, and tourism, jointly conduct the development and reuse of abandoned lands in mining areas. The concept has obvious effects on regional economic improvement: it greatly promotes the regional economy, provides a large number of jobs for the surrounding areas, and fully cultivates the economic value of open-pit mining areas. However, careful planning is required for the application of this concept: first, select a region with a certain historical style to facilitate the construction of cultural tourism elements: second, the cultural tourism planning and route design must be determined with proper supporting facilities and good evaluation of capital balance in order to avoid the "sightseeing without relaxation" phenomenon.

\section{Application of open-pit mining area restoration concept in engineering projects}

\subsection{Project background}

The "Guiding Opinions on Strengthening the Geological Environment Recovery and Comprehensive Management of Mines" issued by the Ministry of Land and Resources in 2016, the overall layout of the "balanced economic, political, cultural, social, and ecological progress" and the "four-pronged comprehensive strategy" strategic layout requires us to firmly establish and implement innovation, coordination new developmental concepts of green, open, and sharing, and strictly implement the "Opinions of the Central Committee of the Communist Party of China on Accelerating the Advancement of Ecological Civilization" and the "Notice of the Central Committee of the Communist Party of China on the Overall Plan for the Systematic Reform of the Ecological Civilization", which call for new progress of restoration and comprehensive management as an coordinated solution of "new and old problems" and historical issues. We are bound to comprehensively improve the level of China 's geological environment restoration and comprehensive management of mines, and make new contributions to the advancement of ecological civilization and the construction of a beautiful China.

In November 2018, the leaders of the Standing Committee of the Shanxi Provincial Party Committee visited the site to conduct supervision and investigation into the ecological management of open-pit coal mines. It was proposed that the mine should take effective measures to completely reverse the passive situation of the restoration and treatment of the surrounding area of the Hengshan Mountain Scenic Area, and significantly improve the surrounding ecological environment in a short period of time, ensuring significant results of restoration and management in three years, and fundamental changes in five years.

\subsection{Geological characteristics and problems of the project}

\subsubsection{Geological characteristics}

Due to non-compliant mining in this mining area, a large amount of rocks in the stripped surface of the open-pit stop were exposed, the ground joints in the subsided area were wide, the dumping site was too high, and spontaneous coal gangue sites existed. The mining area belongs to the topography of low-mountain mountainous area with tectonic stripping (invasion) erosion. The terrain elevation is between 1500 and 1700 meters and is severely cut by surface water with the cutting depth ranging from 30 to 70 meters, the common shape is V-shaped channels. There is a small amount of loess coverage on the relatively lower hillside. The main exposed strata in the area are composed of Carboniferous coal-bearing strata and Mesozoic Cretaceous clastic rocks. Open-pit coal mining in the area and dumping of slag stones lacks scientific and reasonable planning, resulting in disorderly piled up spoil (slag), broken terrain, and serious soil erosion.

In the open-pit mining site, industrial sites (coal storage yards), and dumping (slag) sites, road terrains and surface vegetation were damaged, resulting in serious topographical and landscape damage, as shown in Figure 1.

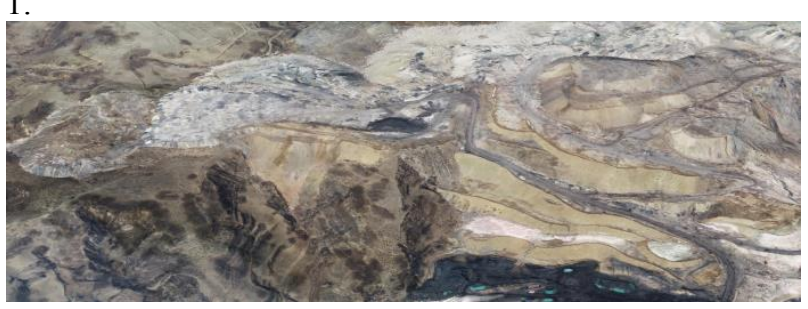

Figure 1 Topography and geomorphology of the restoration area

\subsubsection{Engineering Issues}

The onsite investigation revealed that the rock blocks were hard enough, and no controlling structural surface that had an negative impact on the overall stability of the slope was found, the slope as a whole was basically stable. 
However, due to man-made dumping issues, the dumping site had a large slope, and some of the slope angles reached $500^{\circ}-60^{\circ}$. According to the "Acceptance Requirements of Demonstration Projects of Comprehensive Treatment and Ecological Restoration of Subsided Mining Areas (Shanxi Provincial Department of Ecology and Environment, March 2019)", the slope needs to be at least $35^{\circ}$, so slope instability may occur during construction, and there is no imminent threat at present.

Mining activities stopped in this area in July 2017. According to the onsite survey, currently there are geological disasters such as collapse, landslides (unstable slopes formed by human activities), surface runoff gullies, spontaneous combustion of coal and coal gangue in the mining area. After investigation, no large-scale debris flow disaster has occurred in the mining area, but the large amount of loose slag waste has been randomly deposited on the edges and bottoms of gullies. In case of influencing factors such as heavy rain or melting snow, there is a possibility of debris flow (slag flow).

(1) Unstable slope of the dumping site

The slope height of the dumping site in the mining area is generally above $10 \mathrm{~m}$, the slope angle is generally greater than $35^{\circ}$, and the slope has no reinforcement measures. Therefore, the slope stability is poor, there are many lateral tension cracks on the top, and certain areas has already collapsed, as shown in Figure 2 below.

(2) Rock mass fall in open-pit mining area

The slope of the rock mass in the mining area and the slope tend to be reverse slopes, therefore this kind of slope generally does not have the possibility of large bedding landslides. Geotechnical soils may form unstable blocks due to cutting of structural planes, layers, faults, etc., these unstable blocks are affected by the blasting of mining or the vibration of large rock drilling equipment when breaking rocks, resulting in less stability of these blocks on the slope, and more unstable, collapsed blocked on the stripped bedrock surface, as shown in Figure 3.

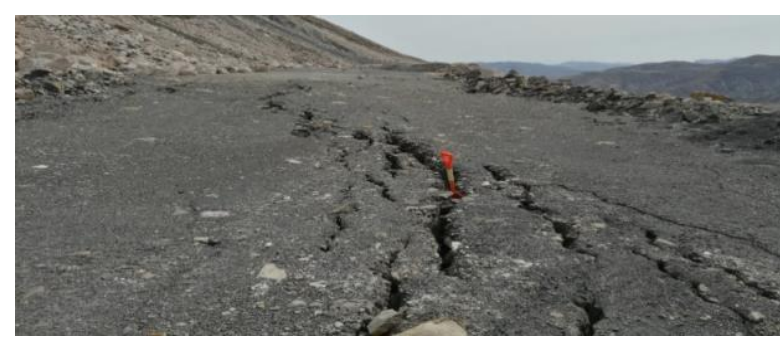

Figure. 2 Tensile cracks at the front edge of the dumping site top

(3) Treatment of toxic and hazardous waste

Coal gangue piles are randomly piled in the treatment area, without sorting, layering, and sealing. When the heat inside the gangue hill gradually accumulates to the combustion point, the residual coal in the gangue pile will ignite spontaneously. After spontaneous combustion, the gangue melts and emits a large amount of harmful gases such as $\mathrm{CO}, \mathrm{CO}_{2}, \mathrm{SO}_{2}, \mathrm{H}_{2} \mathrm{~S}, \mathrm{NO}_{\mathrm{X}}$, among which $\mathrm{SO}_{2}$ is the primary one. The emission of these harmful gases not only reduces the ambient air quality around the gangue hill and affects the physical health of the residents in the mining area, but also often affects the surrounding ecological environment, causing slow growth of trees, increase in pests and diseases, reduction, sometimes even death of crops. See Figure 4 for details.

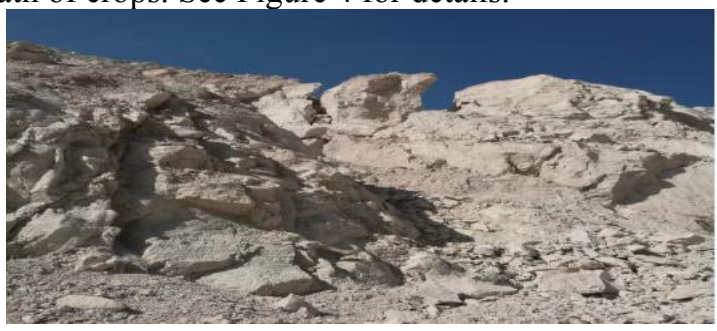

Figure. 3 Unstable blocks

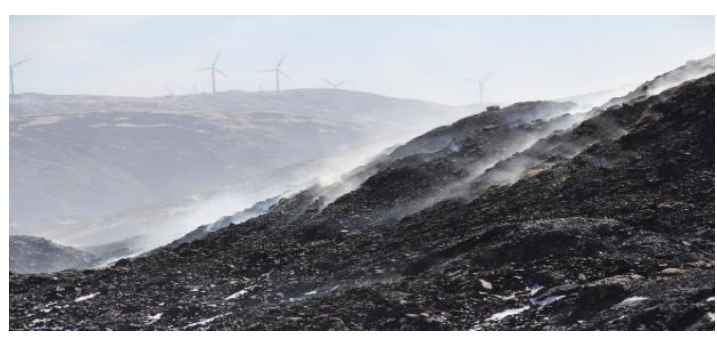

Figure. 4 Spontaneous combustion of coal gangue

The test results of weathered soil samples in some coal gangue areas show that $\mathrm{Hg}$ and $\mathrm{As}$ in the samples exceed the "Soil Quality Standards: Screening Values for Soil Risk Control Standards for Construction Land" (GB36600-2018), and there is a risk of heavy metal pollution.

Table 1. Table of calculation results of the comprehensive index of mine environmental conditions

\begin{tabular}{|c|c|c|c|c|c|}
\hline No. & Evaluation index & $\begin{array}{c}\text { Calculation } \\
\text { Result }\end{array}$ & $\begin{array}{c}\text { Environmental } \\
\text { condition index }\end{array}$ & $\begin{array}{c}\text { Comprehensive } \\
\text { index of mine } \\
\text { environmental } \\
\text { conditions }\end{array}$ & $\begin{array}{c}\text { Evaluation } \\
\text { conclusion }\end{array}$ \\
\cline { 1 - 2 } 1 & Pollution load index & 99.13 & \multirow{2}{*}{48.71} & 34.82 & $\begin{array}{c}\text { Regional } \\
\text { environmental } \\
\text { conditions are }\end{array}$ \\
\hline
\end{tabular}




\begin{tabular}{|c|c|c|c|c|}
\hline 3 & Waste recycling index & 0 & \multirow{5}{*}{25.56} & \multirow{5}{*}{$\begin{array}{l}\text { relatively poor with } \\
\text { few species, and } \\
\text { coal mining has a } \\
\text { greater impact on } \\
\text { surface landscape } \\
\text { damage and land } \\
\text { degradation. }\end{array}$} \\
\hline 4 & Biomass index & 11.94 & & \\
\hline 5 & $\begin{array}{c}\text { Vegetation coverage } \\
\text { index }\end{array}$ & 17.14 & & \\
\hline 6 & Surface damage index & 49.99 & & \\
\hline 7 & Land degradation index & 15.56 & & \\
\hline
\end{tabular}

\subsection{Concept of open-pit mining area restoration}

The mining area is located in the visible area of the famous tourist attractions in Shanxi Province, so its restoration concept should not only meet the "fundamental restoration" and "near-natural restoration", but also introduce the concept of " cultural tourism development of abandoned land" in order to integrate with the sceneries to achieve restoration of open-pit mining areas.

The instability issue of the open-pit mine slope requires mechanical slope clearance, rolling stone removal, rock crushing by weathering, and elimination of potential geological disasters, in order to expose the damaged mining surface. This creates a pathway of coal mining science advocacy along the mining zones to promote the value of local mineral and natural resources. It also explained the techniques and history of coal mining with easy-to-understand language, while addressing the importance of green coal mining and the negative effects of environmental damage on the natural habitats. Finally,

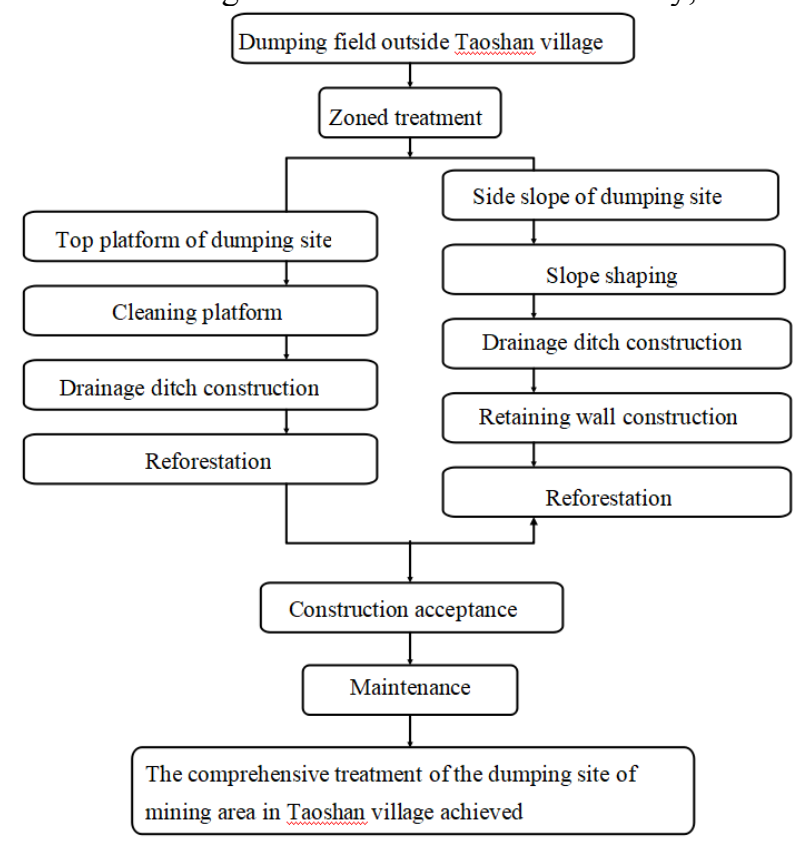

Figure. 5 Technical roadmap for mine treatment

In the dumping site of this mining area, the slope of too high due to disorderly dumping, and the slope foot is too steep (between $35^{\circ}-45^{\circ}$ ). Stepwise grading is required to make the slope foot less $30^{\circ}$ with its height not exceeding 8 meters, a platform is constructed at each level, soil coverage and vegetation are carried out on the platform to ensure that no landscape impact is caused on it will establish a systematic industry in the mining areas that includes factors such as culture, tourism, science popularization, achieving the concept of "tourism development of abandoned land."

Solution to the subsidence problem and spontaneous coal gangue storage sites in this mining area must strictly follow the "Technical Specifications for Vegetation Restoration of Abandoned Lands in Major Mines" (DB 13/T1246-2010), the "Technical Specifications for Ecological Environmental Protection and Restoration of Mine (Trial)" (HJ 651-2013) , and " Technical Specifications for the Ecological Restoration of Coal Gangue Sites "(DB 14/T 1755-2018) to eliminate geological disasters, if necessary, cement can be used to close cracks or gangue layers with a coverage of loess over $80 \mathrm{~cm}$, this completely isolate its internal impact, thus making it possible to conduct scenery construction by planting grass and bushes such as astragalus and sea buckthorn which are compatible to grow in the local condition, achieving the "near-natural restoration" concept to a certain extent.

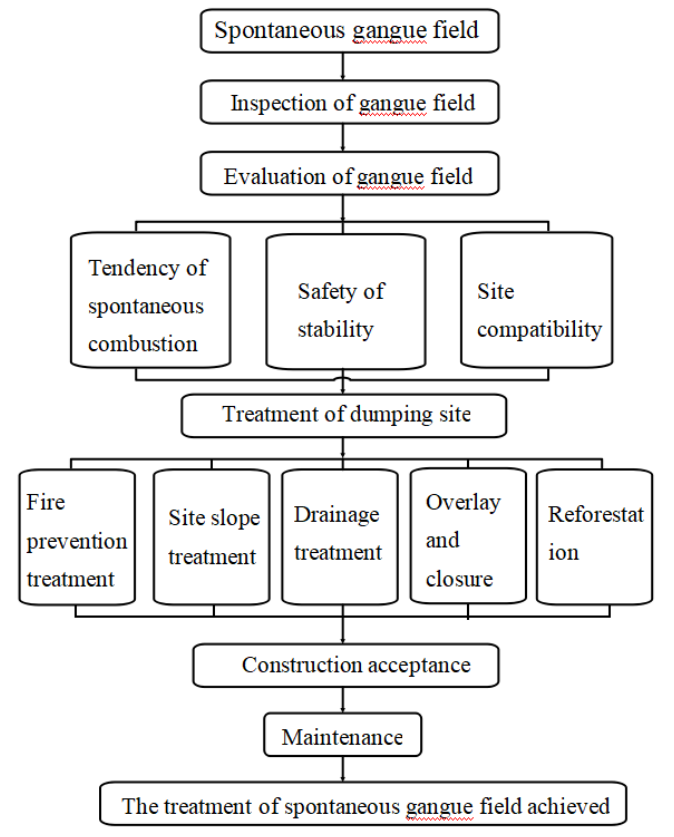

Figure. 6 Technical route of the treatment of spontaneous gangue field

the scenic spots and cultural tourism industry routes, realizing the "fundamental restoration" concept.

\subsection{Design zoning}

\subsubsection{Zoning principle}


The design zoning refers to zoning practice based on the topographic and specific treatment of the land that ensures comprehensive and overall reforestation with near-natural restoration of the outer dumping site. The main principle is the pertinence of the treatment plan and the consistency of landscape.

\subsubsection{Zoning of mine environmental treatment}

According to the site survey and based on the treatment method and the consistency of the landform, the treatment is divided into three parts: the top platform of the dumping site, the slope of the dumping site, and the spontaneous gangue field. Among them, due to landform consistency, the south and north slopes are divided into $T_{S}^{1}, T_{S}^{2}, T_{S}^{3}$ (south slope blocks), and $T_{N}^{1}, T_{N}^{2}, T_{N}^{3}$ (north slope blocks).

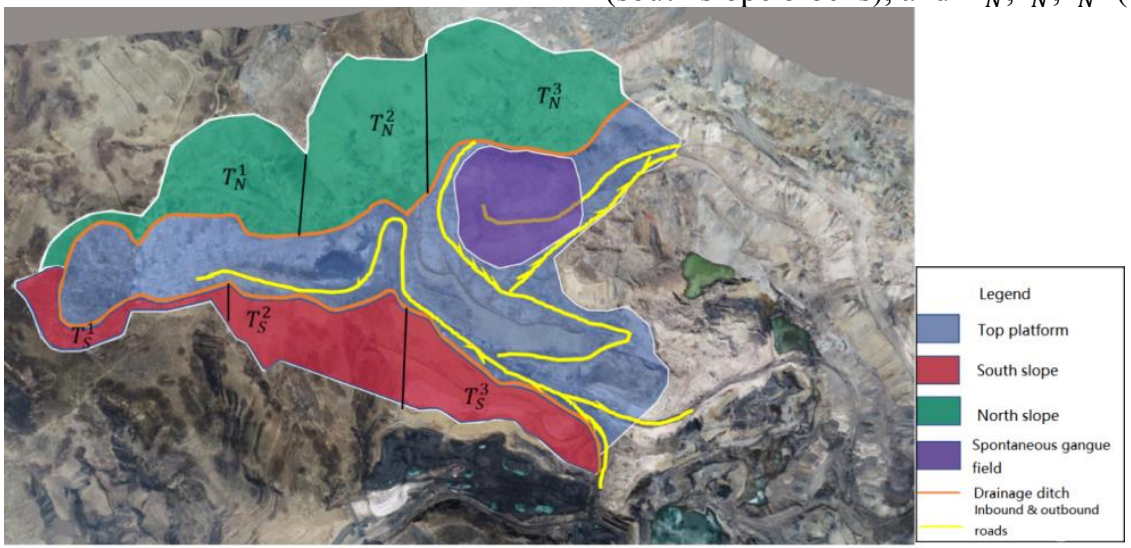

Figure. 7 Schematic diagram of the treatment area of the dumping site outside Taoshan Village

\subsection{Treatment technology of open-pit mining area}

\subsubsection{Landform reshaping technology}

Landform remodeling is the foundation of open-pit mining area treatment. According to the factors such as topographical geology, hydrological conditions, construction methods, landscape requirements and other factors in previous surveys, slope treatment measures such as slope cutting and grading, slope fixing, and landslide prevention \& control were adopted. The slope cutting and grading method is preferred in the treatment of dumping sites. The slope height of each grade should be $8-10$ meters, and the slope angle is generally not greater than $30^{\circ}$. The horizontal plate is set in the form of a reverse slope of $2 \%$ to $5 \%$, the width of the flat plate is not less than 3 meters, and the vertical slope of the flat plate is set to $2 \%$ to $3 \%$.

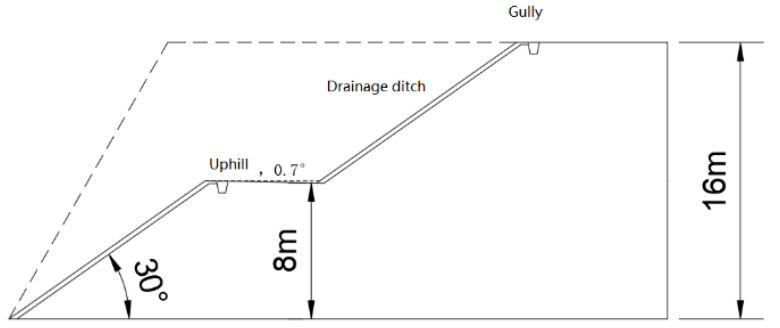

Figure. 8 Schematic cross-section of a cutting feature

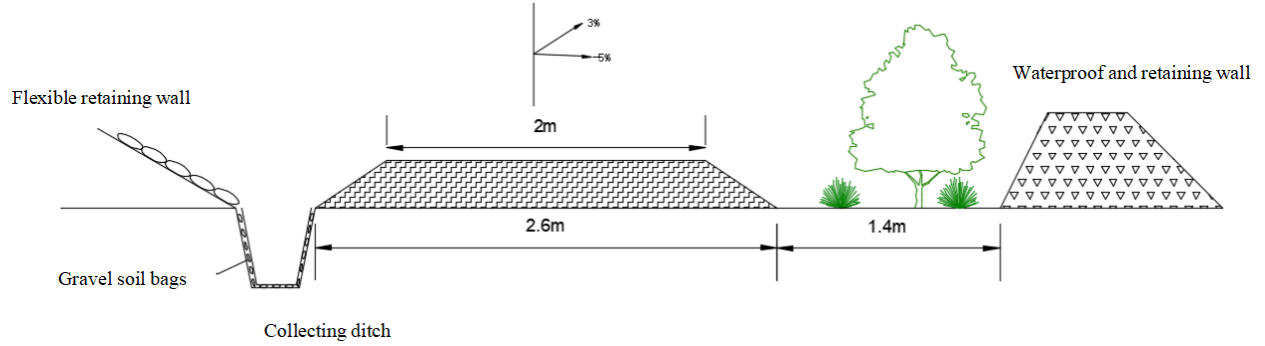

Figure. 9 Cross section of the flat ramp

\subsubsection{Soil and water conservation technology}

Soil and water conservation engineering is the guarantee for the treatment of open-pit mining areas. In order to prevent the sedimentation of the gully caused by slope erosion due to the strong rainfall, mitigate the occurrence of debris flow, and improve the stability of the slope under heavy rain, we built a flexible retaining wall at the slope foot of the dumping site in order to resist the sand and stones that are directly rushing into the ecological catchment ditch, while guided water filtering ensures the smooth flow of water in the ecological catchment ditch. 

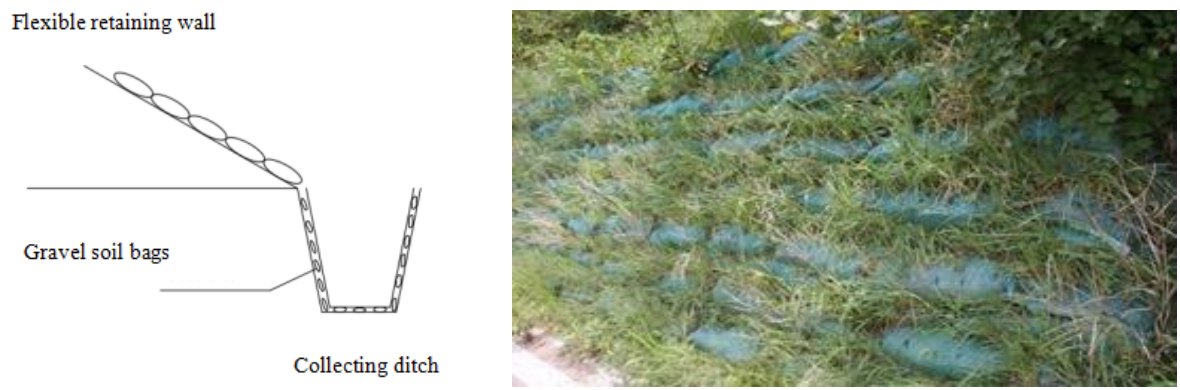

Figure. 10 Effect drawing of flexible retaining wall

\subsubsection{Soil reconstruction technology}

Soil reconstruction technology is an important foundation for afforestation in open-pit mining areas. After the mining area treatment is completed, different thickness of soil cover is applied according to the planting requirements in different areas. According to "Specifications for Design of Soil and Water Conservation Engineering" (GB51018) and "Technical Specifications for Ecological Restoration of Coal Gangue Yard (DB14/T 1755 2018)", after the completion of the dumping site treatment, the thickness of the soil cover should be reasonably determined in accordance with the characteristics of the restorative vegetation. Considering the requirements of soil and water conservation and ecological restoration of the dumping site, the thickness of the soil cover of the designed platform is $50 \mathrm{~cm}$, and the thickness of the slope is $30 \mathrm{~cm}$.

\subsubsection{Vegetation reconstruction technology}

Vegetation reconstruction technology is an important means to restore the original state of the open-pit mining area. The vegetation on the top platform of the dumping site is mainly a combination of trees and bushes. Trees are planted in pit of $1 \times 1 \times 1 \mathrm{~m}$ and the planting distance is 4 meters; bushes are planted with the method of soil removal and replacement by $0.5 \times 0.5 \times 0.5 \mathrm{~m}$, and the planting distance is 2 meters, realizing the concept of "fundamental reforestation" and "near-natural restoration" in some areas.
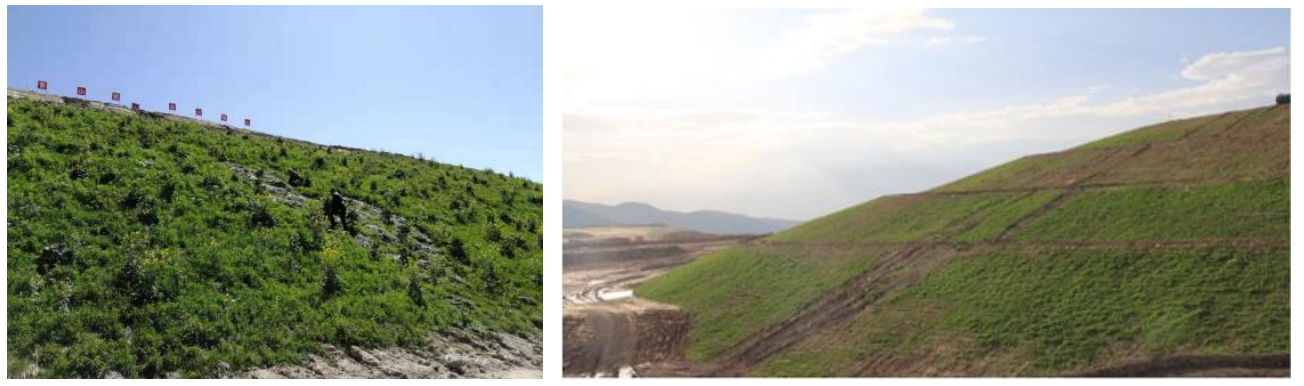

Figure. 11 Real scene of vegetation restoration

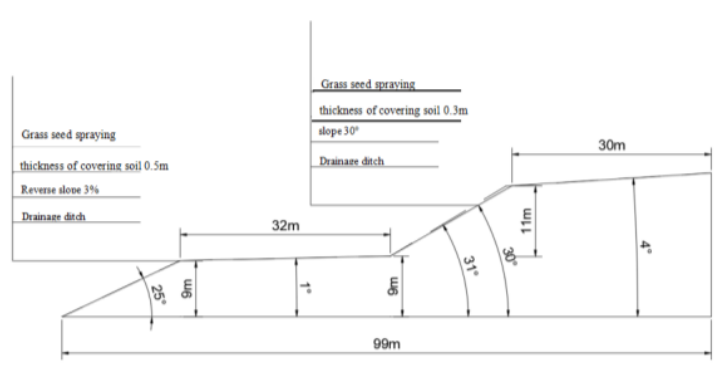

Figure. 12 Sketch map of $\mathbf{T}_{\mathbf{S}}^{\mathbf{1}}$

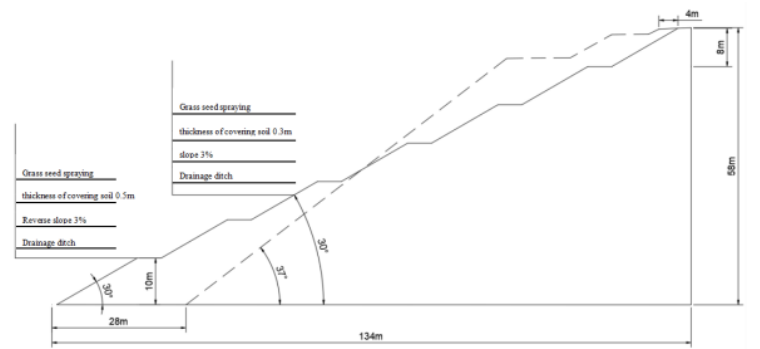

Figure. 13 Sketch map of $\mathbf{T}_{\mathbf{S}}^{2}$

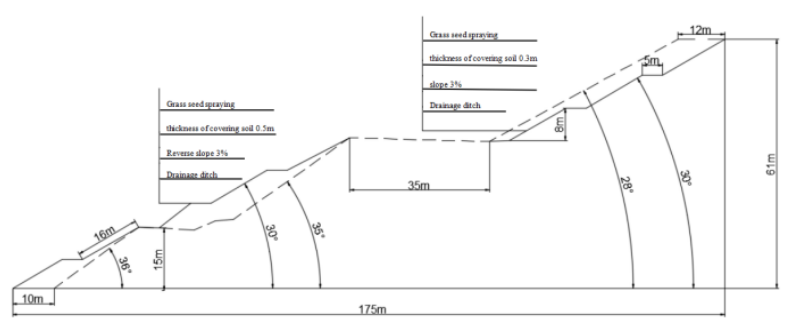

Figure 14 Sketch map of $\mathbf{T}_{\mathbf{S}}^{3}$

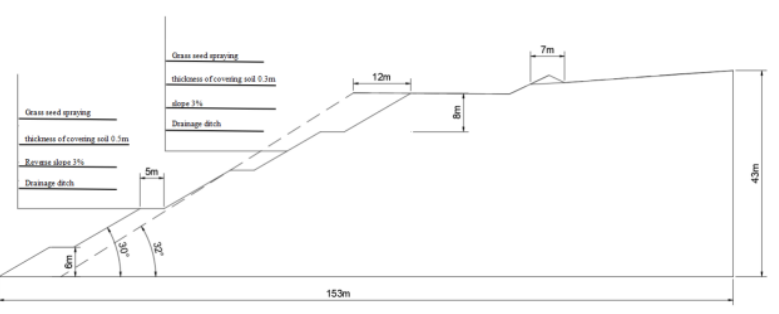

Figure 15 Sketch map of $\mathbf{T}_{\mathbf{N}}^{1}$ 


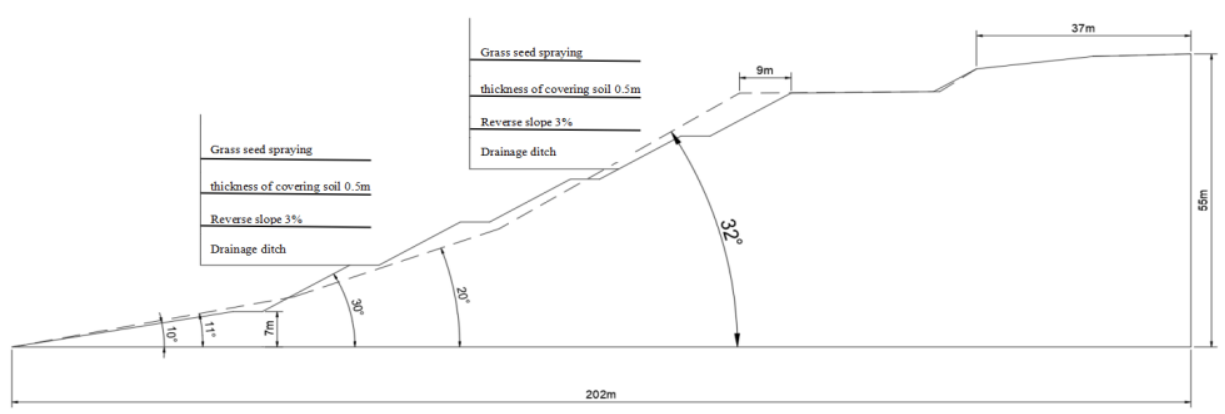

Figure 16 Sketch map of $\mathbf{T}_{\mathbf{N}}^{2}$

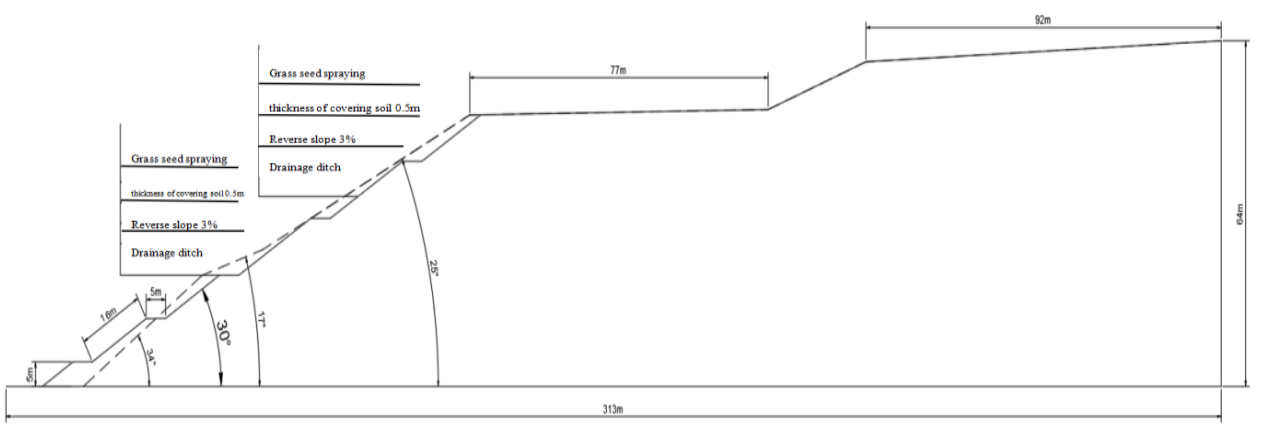

Figure 17 Sketch map of $\mathbf{T}_{\mathbf{N}}^{3}$

\subsubsection{Cultural tourism industry building technology}

After the completion of the treatment of this mining area, a scientific and educational base for the popularization of coal mining and ecological protection will be built along the open-pit mining site: on one hand, it will celebrate the hard work and dedication of coal mine works and Shanxi's characteristic coal mine tourism; on the other hand, it will advocate for the importance of green coal mining and ecological environment protection, spreading the idea that only by protecting the ecological environment can we improve productivity and the concept of "clear waters and green mountains are mountains of gold and silver."
Before the restoration works, the villagers around the mining area primarily employed by the mining industry. After the coal mines were suspended, a large amount of labor was lost and the village economy fell sharply, making it difficult to carry out poverty alleviation in the surrounding areas. Through the above-mentioned repair technologies, the mining area has completed the reforestation of abandoned land in the open-pit mining areas and introduced the industry of cultural tourism in attempt to drive the revitalization of the village economy. The restoration realized economic growth in certain areas with the tourism industry, providing opportunities and employment for local residents, it is a successful practice of the theory of "green mountains and green mountains are golden mountains and silver mountains".

\subsection{Application effects}

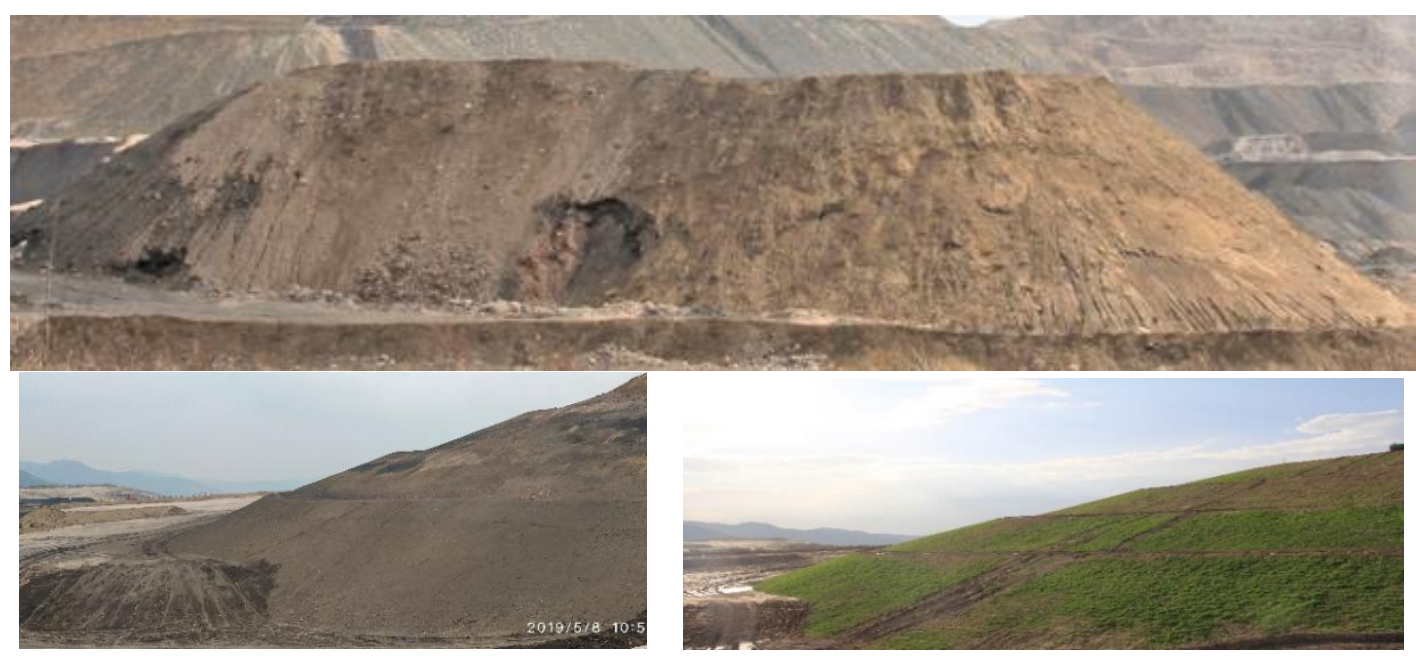

Figure 18 Real scene before, during and after restoration 


\section{Conclusion}

(1) In different mining areas, according to their respective characteristics, such as geographical location, economic conditions, related policies, etc., different concepts are adopted for the restoration and reuse works, and the positioning of open-pit mining area restoration is proposed.

(2) In the restoration and reuse of coal mining areas, national strategies such as national poverty alleviation and rural revitalization should be closely followed and integrated and the theory of "green mountains and green mountains are golden mountains and silver mountains" should be implemented.

(3) For the restoration and reuse of mining areas, four kinds of restoration concepts are proposed, namely "fundamental restoration," "near-natural restoration", "introduction of agricultural and forestry industries", and "cultural tourism development of abandoned land". "Fundamental restoration" is suitable for areas where the economy is relatively backward and inaccessible that needs to restore the natural environment of mines and preliminarily cultivate land with plants; "near-natural restoration" is applicable to areas within the visible range of highways with backward economy, in such areas, there is no need to consider development areas, reshape the geomorphology, restore the original ecological environment, and prevent the impact of landscape destruction; in villages that mainly rely on agriculture and forestry, or areas with value of agricultural production, the concept of "introduction of agricultural and forestry industries" should be adopted to develop the regional labor productivity, providing nearby residents with the opportunity to use their labor, so as to achieve initial improvement of regional economic structure and creation of economic value; in areas with a certain economic base, tourism and cultural industries, the concept of "cultural tourism development of abandoned land" should be adopted, it brings improvement to the ecological environment and realizes diversified development of economic industries on the basis of reusing the abandoned land, achieving upgrade and transformation of local openpit mining areas from the perspective of education, science popularization, and publicity.

\section{References}

1. Ke W., Sha J. (2011) Empirical analysis for the influence of environmental regulation on coal industrial performance in Shanxi province. China Mining Magazine. 20(12):49-52.

2. Li Z.P. (2012) The Development Circumstances of the Basic Environmental Law: From "Human Environment Conference" to "Environment and Development Conference". Journal of China University of Geosciences (Social Sciences Edition). 12(2): 10-17.

3. John C.J. (2000) Setting ecological restoration goals for technical feasibility and scientific validity. Ecological Engineering. 2000(15):171180

4. Cai Q.X., Gao G.J., Shang T. (2002) Optional study of integrating operation of mining and land reclamation in surface mines. Journal of China Coal Society. 27(3): 276-280.

5. Guo Q.X., Bai Z.K., Ji Q., et al. (2006) On Rural Eco-economy Reconstruction in Large Opencast Coal Mine-Taking Pingshuo Mine Area as the Example. Ecological Economy. 2006(5):133-137.

6. Rotherham I.D., Spode F., Fraser D. (2003) Post coal-mining landscape: an under-appreciated resource for wildlife, people and heritage. In Heather M. Moore, Howard R. Fox\& Scott Elliott, Land Reclamation. Extend the Boundaries. 2003:93-99.

7. Zhang S.X. (2009) Quick Photograph of Open-pit Mining and Ecological Recovery Technology. China Mining Magazine. 18 (9) :87-90.

8. Wang D.Q., Wang L.L., Zhu H.K., et al. (2007) Ecological restoration function and ecological agricultural engineering plan in coal mining areas of Mentougou District, Beijing. Transactions of CSAE. 23(11):138-141.

9. Hu Z.Q., Zhao Y.L., Cheng L.L. (2004) Extension of Goal and Meaning of Land Reclamation in China. China Land Science. 18(3):3-8.

10. Fu M.C., Xie H.Q. (2004) Study on Surface Soil Management Mode of Ecological Reclamation in Coal Mining Area. China Mining Magazine.13(4):36-38.

11. Cai Y.P. (2003) Study on Soil Restoration Effect of Green Planting in Shanghai Chenshan Botanical Garden. Journal of Anhui Agricultural Sciences. (03).

12. Song W.D., Chen H.W., Li L.Y. (2009) Establishment and application for spatio-temporal data models of an open-pit stope. Engineering of Surveying and Mapping. 18(3): 1-5.

13. Yi J., Liu G.Q., Jin Y. (2000) Soil and Water Conservation Planning of Pingzhuang West Openpit Coal Mine. Opencast Mining Technology. 3:47 49.

14. Xu L.J., Yan J.P., Gao Y.M. (2008) Environmental impact of coal mining subsided water area in Huainan mining area. Journal of China Coal Society. 33(4):419-422.

15. Cai Z.G. (1990) Theory and method of ground subsidence and water accumulation prediction in Poland. Coal Mine Environmental Protection. (3):17-21.

16. Liu H.P. (2010) The Study of the Filling Effect Based on Coal Gangure Reclaimed Land. Anhui University of Science and Technology.

17. Wang R.X. (2009) Benefits of Comprehensive Control of Subsidence Area Using Coal Gangue in Renlou Coal Mine. Coal Processing \& Comprehensive Utilization. (2):43-44. 
18. Zhao Y., Zhang P., Hu Y.G., et al. (2014) Effect of revegetation types on colonization and growth of biological soil crusts of dumping site in open pit coal mine of Heidaigou. Chinese Journal of Ecology. 33(2):269-275.

19. $\mathrm{Xu}$ Y.G. (2000) Discussion on the Factors Affecting the Stability of Dump Slope [J]. China Mining Magazine. 9(19): 72-73. 